Editorial

\title{
Physiologia: A Progressive Open Access Journal Publishing New Horizons in the Physiology of Life
}

\author{
Philip J. Atherton 1,2,3
}

1 School of Medicine, University of Nottingham, Royal Derby Hospital, Derby DE22 3DT, UK; Philip.Atherton@nottingham.ac.uk

2 Medical Research Council/Versus Arthritis Centre for Musculoskeletal Ageing Research, Royal Derby Hospital, Derby DE22 3DT, UK

3 University of Nottingham Biomedical Research Centre, Royal Derby Hospital, Derby DE22 3DT, UK

check for updates

Citation: Atherton, P.J. Physiologia: A Progressive Open Access Journal Publishing New Horizons in the Physiology of Life. Physiologia 2021, 1, 1-2. https://doi.org/10.3390/ physiologia1010001

Received: 18 May 2021

Accepted: 19 May 2021

Published: 21 May 2021

Publisher's Note: MDPI stays neutral with regard to jurisdictional claims in published maps and institutional affiliations.

Copyright: (C) 2021 by the author. Licensee MDPI, Basel, Switzerland. This article is an open access article distributed under the terms and conditions of the Creative Commons Attribution (CC BY) license (https:// creativecommons.org/licenses/by/ $4.0 /)$.
Physiologia (the Latin origins of Physiology, ISSN 2673-6772), is a new journal aimed at publishing original and review articles demonstrating conceptual advances across the realms of physiology [1]; from humans, to animals, to plants and cells. With a focus upon integrating molecular, cellular, systems and whole organismal function, the field of physiology has very long been recognised as one which advances our understanding of the constructs of life across all species. Charles Darwin, a famed observer of animal physiology and a core founder of principles of evolution, even at that time proclaimed "permit me to assure you that I honour, and shall always honour, everyone who advances the noble science of physiology", when speaking in relation to physiological research as it pertains to human, animal, plant health, and their interrelations.

Since these early, largely observational days, various divisions of physiology have emerged, e.g., comparative, integrative, evolutionary/environmental and cellular physiology (to name a few). This has occurred alongside molecular revolutions underpinned by theoretical and technological advances, e.g., gene sequencing, genetic/cell manipulation and "physiolOMICs" (linking data-rich physiology to complex phenotypes). While helping to shape physiology into the booming field it is today, it has also fractured physiology by creating a blurring of lines across disciplines. On this basis, Physiologia, and I, as founding Editor-in-Chief, intend to retain an all-inclusive remit and to recognise contemporary interdisciplinary physiology, all while maintaining founding principles relating to discovery in the science of life in robust experimental settings.

Reflecting this, research of interest to Physiologia includes, but is not limited to, the following: Human and Animal: muscle physiology, respiration, the circulatory system, neuromuscular function, digestion, endocrine physiology, sport and exercise physiology, reproduction, development, disease, ageing and nutrition; Cellular physiology: using in vivo/in vitro cell biology approaches aimed at positioning cellular physiology in a broader context such as human and animal health and disease; Comparative physiology; to recognise cross-species approaches; and Plant physiology: biochemistry, growth and development, photosynthesis and respiration, transport and translocation, biotic and abiotic stress. All the above areas will also be considered in the context of Evolutionary and Environmental influences, and also while adopting "discipline-hopping" approaches to address complex physiological problems.

Conflicts of Interest: The author declares no conflict of interest. 


\section{Reference}

1. Physiologia Journal Home Page. Available online: https://www.mdpi.com/journal/physiologia (accessed on 19 May 2021).

\section{Short Biography of Author}

Short Biography Professor Philip J. Atherton; Chair of Clinical, Metabolic and Molecular Physiology. Professor Philip J. Atherton was awarded a BSc (1st class) in 2002, and PhD in 2005 on the subject of skeletal muscle molecular signalling networks. Following a postdoc at the University of Nottingham, UK, he was awarded a personal Research Councils UK fellowship, where he studied responses of muscle to nutrition and exercise as a function of age. Thereafter (2012), he was promoted to Associate Professor and then full Professor (2017), both at the University of Nottingham. He has been PI/Co-I on grants $>£ 10 \mathrm{M}$ from UK research councils (MRC, BBSRC), charities (e.g., DMT), industry (pharma/nutritional) and EU sources. He has published >150 non-abstract peer-reviewed articles (H-index 57 (Google Scholar), with $>15,000$ citations (rate $>2500$ /year), an i10 index of 108, and 7 invited book chapters. The overarching direction of his current work involves the combining of experimental and medical physiology with the application of stable isotope tracers, OMICs, and in vivo/vitro molecular biology to discover predictors of, the mechanistic basis for, and means to mitigate musculoskeletal declines in age and disease(s). 